OPERATION FOR RELIEF OF STRANGULATED IN. GUINAL HERNIA, ALSO FOR ITS RADICAL CURE, IN A CHILD TWO YEARS OF AGE.

Bx GEORGE BUCHANAN, M.D., F.R.S., Professor of Clinical Surgery, Glasgow University.

OpErations for the relief of strangulated hernia in young children are sufficiently rare to warrant the report of the following case.

John M., aged 2 years and 4 months, was admitted to the Western Infirmary, Glasgow, on September 25th, at 10 P.M. The history of the case is that, when a few days old, a swelling was observed in the scrotum on the right side, and subsequently on the left. These, which could be reduced in size, were believed to be herniæ, for which a double truss was worn, but without much effect, as the rupture on the left side repeatedly came down, and the swelling on the right never was completely reduced. This state of affairs was allowed to go on till the day before the child was brought to the hospital, when, after a severe fit of crying, the swelling on the left side of the scrotum suddenly increased, became very tense, and could not be returned. During the night the child suffered much pain, and, in the morning, vomiting occurred. In the afternoon a medical man was called, who endeavoured, by careful and continued manipulation, to return the hernia, but without effect.

When the child was taken to the hospital, the house-surgeon, finding vomiting still persisting and the tumour firm and unyielding, sent for me.

I put the child under the influence of chloroform, and again tried taxis, but without avail. I then cut down and relieved the stricture, which was very tight. The intestine, which was dark purple in colour, was returned after gentle pressure. I then drew the pillars of the canal together with three silver wire-sutures, in the way I do when performing the operation for the radical cure in ordinary circumstances. The wound was dressed antiseptically.

There was no hernia on the opposite side, but distinct enlargement of the testicle. Possibly this, with a certain quantity of fluid in the sac, may have been the state of matters throughout.

It is unnecessary to give details of the progress of the case, which terminated by the complete agglutination of the inguinal canal boundaries, and the radical cure of the hernia.

REMARKS. - This is the only case, within a hospital-experience of twenty-five years, in which I have had to operate on so young a child. And from a pretty extensive inquiry, I learn that the experience of other surgeons is similar. Some surgeons are under the impression that the operation is almost never imperative. But the experience of one of my colleagues, who operated on a child equally young a few months ago, shows that sometimes in children, equally as in adults, operative prosedure is too long delayed. In the case referred to, attempts at taxis had been frequently repeated, before the child was sent tc the hospital, and the bowel was found approaching to gangrene, and the result was fatal. But, further, I hold that delay in such cases, or even in those which have resisted very moderate attempts at reduction, is uncalled for and unwise; because advantage may be taken of the child being under chloroform to perform the radical cure ; it adds nothing whatever to the danger of the operation, and brings about a most desirable result. Every year's experience convinces me that there are a very great number of children in whom cure by truss is, or at all events has become, totally impracticable. Theoretically, every child with a hernia should be provided with a truss which will keep it up ; and every mother ought to be instructed so to manage the truss that the hernia will never be allowed to come down. But, practically, in hundreds of infants, this is impossible.

\section{PERIOSTITIS FOLLOWING TYPHOID FEVER.}

\section{BY JOHN D. HAYWARD, M.D.Lond., LIVERPOOL.}

Periostitis as a sequela to typhoid fever appears to me to be more common than is generally supposed; in the course of the last few years, I have met with several cases. In one case the periostitis did not suppurate, and the patient did well ; in another, periostitis appeared about several of the long bones; suppuration occurred, with external discharge ; but, after new attacks of periostitis had ceased to occur, and the old sinuses had healed (which they did readily), the patient sank under acute phthisis, of which, previously to the enteric attack, there had been no evidence. The attacks of typhoid fever in which I have noticed this sequela have been sercre ones.

The following case is at present under treatment.

Minnie $F$. aged 16, $w$ is first seen by me on August 25th, 1884 ; she had been suffering with fever and diarrhœa for the preceding week, previously to which she had been a strong, healthy girl. The patient was found to have well-marked typhoid fever; there was deafness; the stools were characteristic. So, to some extent, was the tongue; there was gurgling and tenderness in the right iliac fossa, the morning and evening temperatures varied in the manner common in this fever, and for several days the temperature remained between $104^{\circ}$ and $105^{\circ} \mathrm{Fahr}$. The patient went through an ordinary but severe and prolonged attack of enteric fever. After the diarrhoea and abdominal tenderness had ceased, the brown dry tongue became almost normal, and the appetite good; but, although all intestinal lesion appeared to be recovered from, it was noticed that the temperature ran up every day to $104^{\circ} \mathrm{Fahr}$. or thereabouts, and was never normal ; night-sweats, anorexia, occasional shiverings, and increased loss of flesh were observed. Some local cause for the general pyrexia was searched for in vain; the lungs appeared normal, and there was no cough ; periostitis, being quite unsuspected, was not inquired after. The cause of the pyrexia puzzled me very much until October 11th, when the patient mentioned that her leg was painful and swollen. On examination, a swelling, about the size of half a small orange, was found in front of the left tibia ; it was tender and elastic. On the 13th the swelling fluctuated, and was opened, when about half an ounce of pus escaped; the leg was poulticed, and about an ounce of pus was altogether discharged before the abscess and sinus were healed, which was the case in three days. The girl recovered appetite and strength, but on the 19th of October she was found crying because her other leg was paining. A similar swelling was found over the middle of the right tibia, the left leg being now perfectly well. The second swelling was opened, and discharged about an ounce of pus; it also was quite well in three days. On November 3rd, a similar fluctuating tumour occurred at the lower end of the right tibia (quite separate from the preceding); this contained blood-clot and a little pus. It is now discharging and contracting. There is at present no sign of inflammation or tenderness over any other bone or joint, and the patient is slowly improving in general health. The periostitis has not been of a serious nature locally, and indeed an early opening was never urgently required. It seemed as if only the outer surface of the periosteal membrane were involved. No necrosis took place.

REMARKs. - Some of the text-books at my disposal do not mention periostitis as a sequela of enteric fever, and none that I have consulted give it a prominent place ; they merely mention it, and do not discuss its origin, frequency, ur prognosis. It is possible that this local inflammation is due to the tendency to degenerative changes induced by the exhausted condition of the system after a severe enteric fever, resembling thus some of the commoner sequelæ of this fever. Or, there may be a septicæmic origin in some cases, just as some of the instances of parotitis, marasmus, and phthisis after enteric fever are supposed to arise. The course of temperature in the case mentioned above, and the development of abscesses of the lung in my previous case, are interesting from this point of view. In a late number of $L e$ Progrès Medical, Routier divides these cases into those where only the external layer of periosteum is affected, those that are only subperiosteal, and those where the bone is also affected. I have never seen one of the latter class. Routier believes the local inflammation is always the result of injury, a blow, or a violent muscular contraction, these causes being sufficient to induce the condition when the body is in the enfeebled state after an attack of enteric fever. No such causes could be traced in my patients, and it is difficult to see why, if the condition is to be so accounted for, periostitis should be so much commoner (as I believe it to be) after typhoid fever than after other diseases which exhaust and enfeeble the system to an equal extent. It would be interesting if some collection of the cases where this sequela occurs could be made, and if we could have some authoritative opinion as to its frequency, cause, prognosis, prevention, and treatment. It is interesting that my cases have been in young persons, where the growth of bone is possibly not completed, and the active condition of the periosteum may in this way predispose to inflammation of the part.

Cremation in France.-At the annual meeting of the Paris Cremation Society, the President, M. Koechlin Schwartz, stated that the law proposed by MM. Gambetta, Paul Bert, Tony Révillon, and many Republican deputies, is not yet passed. Cremation remains at present illegal in France. It was generally suggested in the report that there was nothing to prevent cremation in the hospitals. The President insisted on the great security for the public health by the adoption of the system, and mentioned that in Italy there had been 396 cremations, and in Germany 186. The tariff for the transport of corpses to Italy for cremation was circulated. It is rather high, and can only be resorted to by rich families. 